\title{
A new classification of deployable structures
}

\author{
Amela Šljivić ${ }^{1, *}$, Slađana Miljanović ${ }^{1}$, and Muhamed Zlatar ${ }^{1}$ \\ ${ }^{1}$ University of Sarajevo, Obala Kulina bana 7/II, 71000, Sarajevo, Bosnia and Herzegovina
}

\begin{abstract}
Deployable lightweight structures are studied in the disciplines of architecture, civil engineering, aerospace engineering, mechanical engineering and other fields of their application. The research into these structures in individual fields resulted in a large amount of data sorted out by numerous classifications. The previously made classifications proposed by different authors are presented in this paper by the usage of reasonably unified tables that enabled a direct insight into the essential characteristics of these structures, their analysis and mutual comparison. One of the results of these analyses is the proposal for the unified classification given in a separate table in this paper. The results of interdisciplinary studies have been collected into a unified classification which could be applied for the research in different scientific fields, presenting the basic types of these structures, including individual elements and details with their characteristic features. The proposal of the unified classification of deployable structures is made according to the application of the basic elements used for structure forming. The suggested classification, with the review of the results of the present research, is a significant starting point for the scientists in different disciplines and it provides a detailed insight into the studied characteristics of these structures.
\end{abstract}

\section{Introduction}

The advantages of the application of deployable structures in architecture were recognized in the 1960s. However, the complicated process of designing and implementing these structures resulted in their rare application and very few examples completed in architectural practice. The research of these structures on the interdisciplinary level resulted in a large amount of data sorted out in different scientific databases, and that is why their grouping with precisely defined parameters and criteria is necessary. These structures can be classified into specific categories according to different criteria such as type of structural element, the geometrical and kinematic characteristics of the structure, or by their application in particular areas of engineering. According to [1] the purpose of the classification system is to hierarchically present the principles that define the group of discussed objects.

This paper brings the analysis of the classifications by the following authors: F. Escrig [3], A. Hanaor and R. Levy [1] S. Pellegrino [4] C. Gantes [5] K. Korkmaz [6], N. De Temmerman [7], A. E. Del Grosso and P. Basso [8], and E. Rivas Adrover [9]. These

${ }^{*}$ Corresponding author: $\underline{\operatorname{amelag} @ \text { af.unsa.ba }}$ 
classifications are given in the unified tables (Fig. 1.), sorted by the basic types within which the groups with the described characteristics are set aside and include the literature review at a multidisciplinary level. Due to the limitation of this paper, just two of classifications are shown in the unified tables with details, while others are presented in [2].

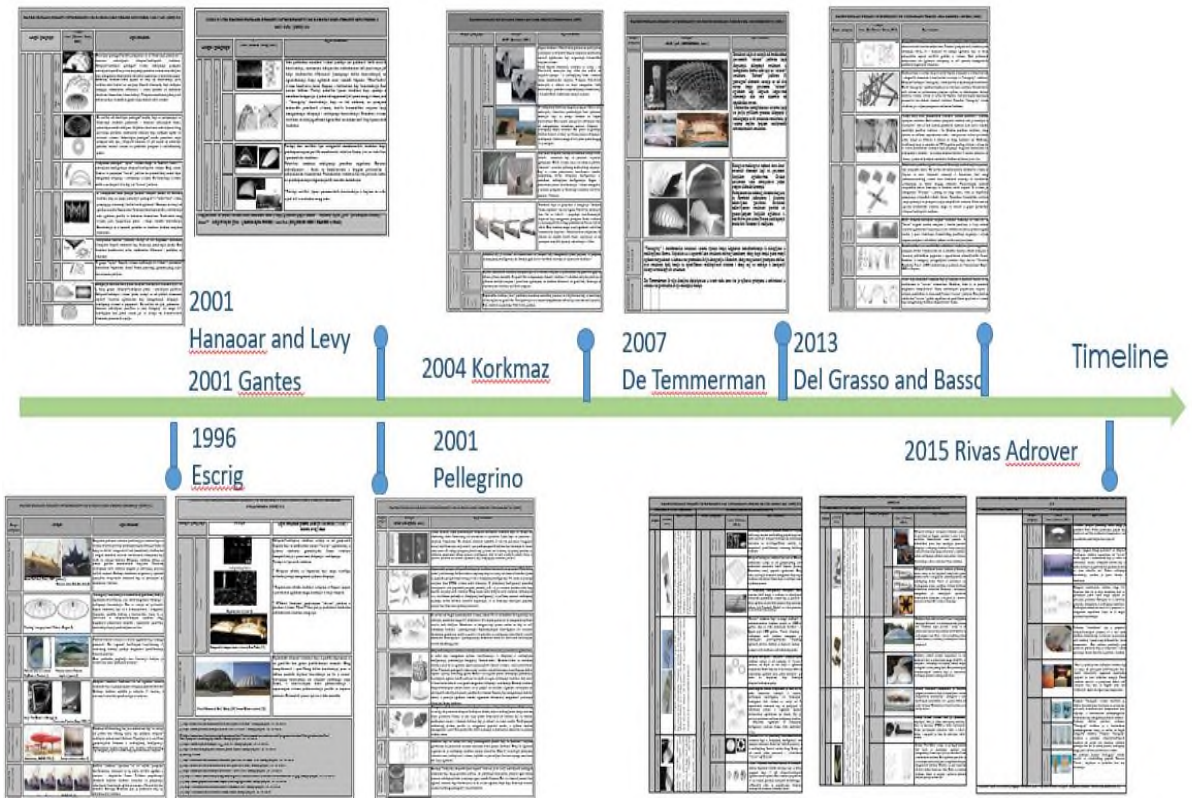

Fig. 1. Review of previously made classification presented in the unified tables.

The progress in the field of deployable structures can be monitored by comparing the classifications suggested by Escrig [3] and Rivas Adrover [9]. The most significant advancement of these structures can be monitored throughout the development of modern origami-inspired deployable structures or deployable tensegrity structures that are capable of changing configuration from the compact folded form into unfolded form by using specific mechanically supported systems. However, the potential for their application in the field of architecture has not been applied to the full.

The proposal of a unified classification of deployable structures which presents the result of the previously described research, enables a multidisciplinary approach to further research, application, as well as to the development of new systems of deployable structures.

\section{Review of previously made classifications}

Escrig (1996) proposed a classification based on the tendencies of the development of deployable structures in the period from 80 's to 90 's of the 20th century. According to [3] structures have been grouped into several categories: tensile folding structures, retractable roofs, umbrella structure, mobile structure, foldable structures, deployable structures, tensegrity and lifting structures. This classification has not shown the difference between deployable and demountable structures. Tensegrity and lifting structures are presented in this classification, although they do not belong to the group of deployable structures in that period.

The classification of deployable structures proposed by Hanaor and Levy (2001) is presented in Table 1 and Table 2. Deployable structures were classified according to the morphological aspects and kinematic characteristics of the structure. According to [1] the 
kinematic properties of the structure significantly influence on the complete technological process of production and increase the total cost of the construction. Tables 1 and 2 have shown that bar structures represent the largest group of deployable structures, which leads to the conclusion that these systems have great potential for application in different fields of engineering. Pellegrino (2001) has divided deployable structures into several categories without proposing a new classification, but with clearly defined and described groups of those structures in the book Deployable Structures. Pellegrino develops deployable structures for their application in different fields of aerospace engineering. According to [4] structures are grouped into the following categories: coiled rods, flexible shells, structural mechanism, membranes, rigid-panel structures, tension truss antennas, and retractable dome.

By comparing the proposed classification with the previously presented, it is clear that a large number of identical structures are grouped in different ways. Pantograph systems in this classification are presented in the group of "structural mechanisms". The retractable domes are now separated as a special group of deployable structures, while they have been grouped into pantograph systems in classifications proposed by Hanaor and Levy. However, new systems have been introduced, which have direct application in space engineering, such as flexible shells, coiled rods and tension truss antenna.

The classification proposed by Gantes (2001) recognized the distinction between structures whose applications were primarily terrestrial and those designed to be applied in the space. The classification of structures with the terrestrial application does not differ significantly from the previously presented classification, and generally was based on the division into five groups [5] : pantographs, membranes and pneumatics, cables, 2D panels, and retractable roofs.

Korkmaz presented the classification of kinetic architecture in his $\mathrm{PhD}$ dissertation, where under the term „kinematic architecture” generally refers to structures or their components with different mobility or different geometric movements (Table 3). According to [6] kinetic architecture is divided into two groups: "objects with variable geometry and movements" and "objects with variable locations or mobilities". The difference between deployable structures and structures that can move from one place to another, but represent the demountable structure is emphasized with this division. Korkmaz proposed classification of deployable bar structures according to the type of cover material that was used, while the previous authors did not observe this aspect. From the proposed classification, we can conclude that additional stiffness of the bar systems can be provided by applying rigid cover materials.

De Temmerman has given a remarkable contribution to the development of deployable structures in the last ten years. In his proposal [7] deployable structures are grouped according to their structural system. Division in a smaller number of groups enables systematic version from all above-mentioned classifications with a detailed description of groups. Deployable structures are grouped according to the precisely defined parameters and criteria into the following categories: spatial bar systems, foldable plates, membrane, and tensegrity systems.

Del Grosso and Basso (2013) proposed classification that has been based on the kinematic properties of the structure. According to their transformation process, deployable structures are divided into two categories [8]: deformable structures and mechanisms with rigid connections. A particular pneumatic structure category with integrated deployable mechanism is presented in this classification. The authors first use the term „origamiinspired structure" in their classification for the special category of deployable hinged plates. In the category of "rigid link mechanisms" identical structures are presented, as well as in the other classification. However, the authors have been used for the first time the 
term „modified scissor-like elements“ in their classification, and proposed an entirely new group of deployable structures called morphological truss structures.

Table 1. Classification of deployable structures by Hanaor and Lavy (2001) - (part 1/2). Note: All illustrations and descriptions in this table were used from [1].

\begin{tabular}{|c|c|c|c|c|c|c|}
\hline \multicolumn{7}{|c|}{$\begin{array}{l}\text { CLASSIFICATION OF DEPLOYABLE STRUCTURES BY HANAOR AND LEVY (2001) } \\
\qquad 1 / 2\end{array}$} \\
\hline \multicolumn{5}{|c|}{ Groups and subgroups } & $\begin{array}{c}\text { Example } \\
\text { Source: [1] }\end{array}$ & $\begin{array}{c}\text { Description } \\
\text { was made according to [1] }\end{array}$ \\
\hline \multirow{6}{*}{ 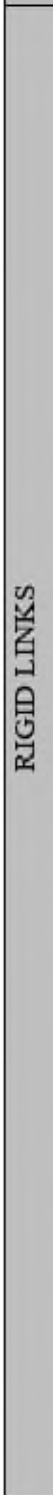 } & \multirow{6}{*}{ 药 } & \multirow{3}{*}{\multicolumn{2}{|c|}{ 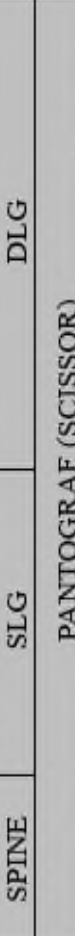 }} & $\frac{\text { 偂总 }}{\text { 总 }}$ & & $\begin{array}{l}\text { Double-layer pantograph grids are suitable for } \\
\text { forming single and doubly curved shapes of the } \\
\text { deployable structure. Deployable pantograph systems } \\
\text { are requiring the application of curved surfaces as } \\
\text { they have the necessary structural thickness which } \\
\text { enables predominantly axial stresses in structures. } \\
\text { However, a distinctive feature of this type of } \\
\text { structures is the low bending stiffness of the bar } \\
\text { elements that significantly reduce the structural } \\
\text { efficiency and creates the need for additional } \\
\text { stiffening elements in the structure. Application of } \\
\text { the membrane cover in these structures could provide } \\
\text { better structural stiffness. }\end{array}$ \\
\hline & & & & 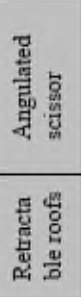 & & $\begin{array}{l}\text { In contrast to the double-layer pantograph grid } \\
\text { (which is used to form the structure of the single and } \\
\text { doubly curved shape), single-layer grid requires a } \\
\text { double curvature to achieve the necessary structural } \\
\text { thickness, that significantly affects the load-bearing } \\
\text { capacity of the system. However, single-layer } \\
\text { pantograph grid does not have the required stiffness } \\
\text { for practical application in architectural practice. }\end{array}$ \\
\hline & & & & 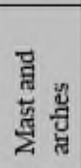 & & $\begin{array}{l}\text { Using a pantograph "spine" system enables forming } \\
\text { a flat or curved configuration of deployable system. } \\
\text { This system is formed by connecting the scissor units } \\
\text { on a prismatic basis. }\end{array}$ \\
\hline & & \multirow[t]{2}{*}{ 宸 } & \multirow[t]{3}{*}{$\frac{\pi}{4}$} & 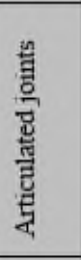 & & $\begin{array}{l}\text { In cases where there are special requirements for the } \\
\text { load-bearing capacity of structures that could not be } \\
\text { fulfilled with pantograph or "cable-strut" system, the } \\
\text { concept of "articulated joints" have been used. This } \\
\text { system consists of articulated bar elements that form } \\
\text { double-layer grids and additional elements that } \\
\text { enable the articulation of joints. }\end{array}$ \\
\hline & & & & 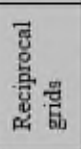 & & $\begin{array}{l}\text { The reciprocal frame structure consists of mutually } \\
\text { indirectly supported bar elements that form single- } \\
\text { layer grids. These structures are characterized by low } \\
\text { structural efficiency. }\end{array}$ \\
\hline & & 宸 & & 总 & & $\begin{array}{l}\text { In group "bars" and category "spines" there are } \\
\text { systems with spatially connected bars that are } \\
\text { making the shape of a regular geometric body as a } \\
\text { base unit. }\end{array}$ \\
\hline
\end{tabular}


Table 2. Classification of deployable structures by Hanaor and Lavy (2001) - (part 2/2 ). Note: All illustrations and descriptions in this table were used from [1] .

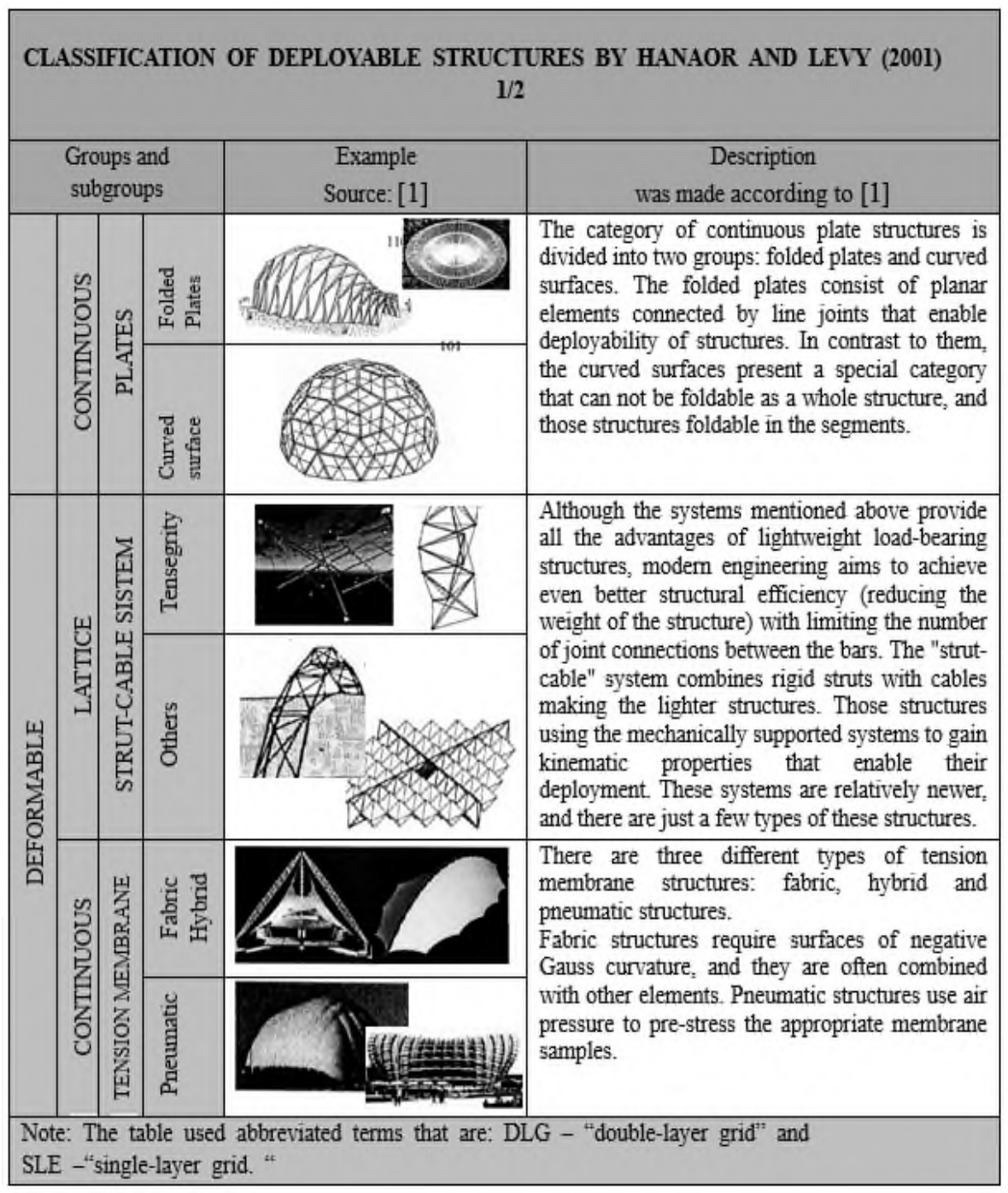

Classification of deployable typologies by Rivas Adrover is presented in the form of diagrams in her book Deployable Structure (2015). According to [9] deployable structures were divided through two different approaches to the development of the deployable system of the structure. The approach based on the structural components of deployable mechanisms is classified as "structural component". "Generative Techniques" is a second approach inspired by natural biological structures combined with origami techniques. The proposed classification of the structure has been grouped into groups with subgroups. The division of structural components into deformable and rigid components is extended with two new categories: flexible and combined. This classification provides a better insight into the new architectural structures that are not presented in classifications before. Along with 
the architectural structure, the structures that have their application in the space are equally represented, which provides a multidisciplinary application to this classification (Fig. 2).

Table 3. Classification of kinetic architecture by Korkmaz (2004). Note: All illustrations and descriptions in this table were used from [6].

\begin{tabular}{|c|c|c|c|c|}
\hline \multicolumn{5}{|c|}{ CLASSIFICATION OF KINETIC ARCHITECTURE BY KORKMAZ (2004) } \\
\hline \multicolumn{3}{|c|}{ Groups and subgroups } & Example & Description \\
\hline \multirow{4}{*}{ 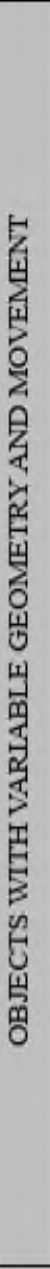 } & \multirow{3}{*}{ 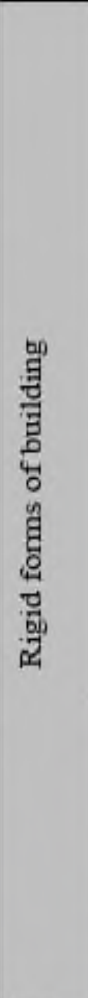 } & 变 & & $\begin{array}{l}\text { Deployable bars structures with flexible cover } \\
\text { material are composed of rigid bar elements } \\
\text { interconnected by joints that assure the linematic } \\
\text { properties of the system. Due to the bar elements, } \\
\text { the structure consists of flexible materials that } \\
\text { serve as protection from external influences and } \\
\text { in the unfolded configuration has membrane } \\
\text { properties. The usage of flexible material } \\
\text { compared to rigid materials enables lighter } \\
\text { structures. They were often used in combination } \\
\text { with short span kinematic structures. }\end{array}$ \\
\hline & & 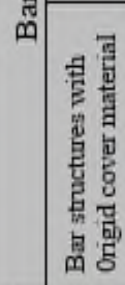 & & $\begin{array}{l}\text { Rigid covering materials that are connected } \\
\text { directly to the bar structure presenting the } \\
\text { alternative material when it is not possible to } \\
\text { apply the flexible material. Rigid solid panels } \\
\text { must be designed to allow a smooth deployment } \\
\text { process. These panels provide additional stiffness } \\
\text { of the structures. }\end{array}$ \\
\hline & & 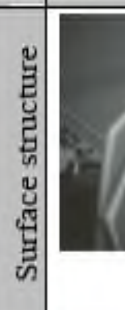 & & $\begin{array}{l}\text { Deployable surface structures consist of planar } \\
\text { elements that are connected by line joints. The } \\
\text { shape of the system depends on the choice of basic } \\
\text { elements and the principles of their mutual } \\
\text { coupling. This system transforms between the } \\
\text { compact form into an extended configuration. } \\
\text { They have been used for different application in } \\
\text { architecture. }\end{array}$ \\
\hline & 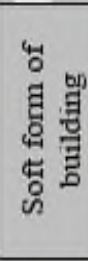 & & & $\begin{array}{l}\text { Structures grouped into the category of "soft } \\
\text { forms of building" use lightweight, flexible } \\
\text { materials such as fabrics and have a } \\
\text { transformation capacity that allows the } \\
\text { transformation from its original shape into } \\
\text { another predetermined stable geometrical shape } \\
\text { of structures. }\end{array}$ \\
\hline \multirow{3}{*}{\multicolumn{2}{|c|}{ 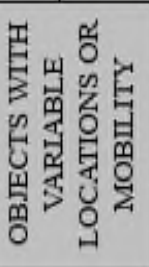 }} & \multicolumn{3}{|c|}{ Portable buildings } \\
\hline & & \multicolumn{3}{|c|}{ Relocatable buildings } \\
\hline & & \multicolumn{3}{|c|}{ Demountable buildings } \\
\hline
\end{tabular}




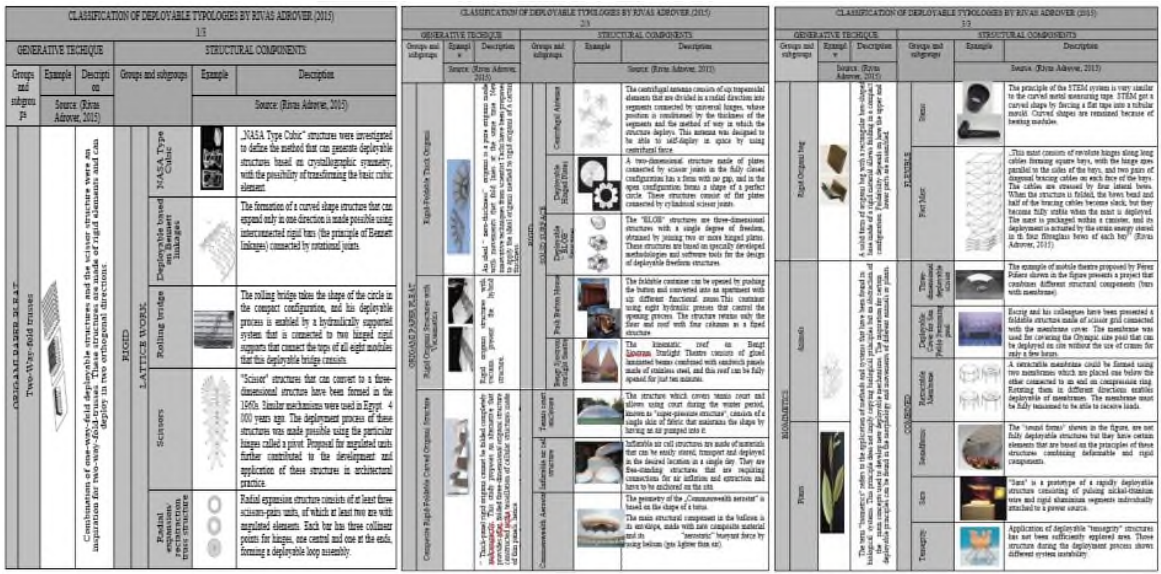

Fig. 2. Review of classification proposed by Rivas Adrover (2015) presented in the unified tables.

\section{Comparison of previously made classifications and guidelines for a new classification}

The analysis and comparison of the classifications of deployable structures resulted in the conclusion that the previously made classifications very often emerged with the aim of assigning the membership of the existing architectural or space structures to a specific group, often without the appropriate definition of specific criteria that significantly determine them. The comparisons of the previously made classifications have been made to form a new classification that will unify all the knowledge about deployable structures in one place.

In this paper, the analysis of classification presented in chronological order resulted in the conclusion that significant application of deployable structures has not been realized in the field of architecture, and that the potential of these structures was not fully exploited.

By analyzing Escrig [3], we concluded that there is a strong need for a complete separation of demountable and deployable structures, which Korkmaz [6] offered in his classification of kinetic architecture. General division in presented classifications into the structures with rigid links and deformable components, used by many authors could be confused as these authors have different ways of defining the basic characteristics of the groups for which they use identical terms. Deployable bar structures are the largest group with great potential for application in various fields of engineering. However, these classifications do not entirely present all the categories of these systems. Deployable bar structures are divided into multiple groups among which scissor structures stand out. De Temmerman [7] uses the division of scissor systems into three groups (translational, polar, and angulated), while Del Grosso and Basso [3] use and introduce the term "modified scissor-like elements" in their classification. These elements represent a significant improvement in the development of deployable structures. The classification by Hanaor and Levy [1] indicates the need for illustrated descriptions of geometrical forms of those structures as they would provide researchers with a complete insight into the possibilities of these systems.

In their papers Hanaor and Levy [1] and Korkmaz [6] took into account the achievement of additional stiffness of deployable bar structures and suggest the application of membrane covers, rigid cover materials, and cables in different constellations. This points to the need for integrated observation of deployable structures.

By analyzing Pellegrino [4], new systems have been isolated for application in space. Gantes [5] completely separates deployable structures for space application and those for 
terrestrial application, while Rivas Adrover [9] perfectly connects all these structures in a unified classification. However, large number of groups in this classification makes it extremely difficult for researchers starting to work with these structures.

The classification proposed by De Temmerman [7], which divided deployable structures into four groups, is one of the guidelines for a new classification suggested in this paper.

\section{New classification of deployable structures}

The main features of deployable structures originate in the geometry of the basic elements, their transformability regarding the position and possibilities of special hinge between elements, and the joints between the units. This enabled the identification of the basic criteria for the classification of deployable structures. The proposal of the unified classification of deployable structures was made according to the application of the basic element used for structure forming (Tables 4 and 5). Therefore, four primary divisions can be distinguished: bar, plate, spatial, and combined elements. The basic unit in the category "bar elements" consists of two bar elements connected by special hinge, while the basic unit in the category "plate elements" are mutually connected plates by line hinges as shown and described in Table 5. The structures that consist of elements that are given certain functions and applications only after the spatial geometrical form of the element has been achieved are presented in the group "spatial elements". This group includes all types of pneumatic constructions among which these stand out: air inflated, air supported and pneumatic constructions with deployable mechanism. The group "combined elements" include the combination of two or more different basic load-bearing deployable elements. Umbrella type structures [10], membranes [11], tension trusses antennas [4], and other systems that combine various deployable basic elements to form load-bearing structures are in this group.

In terms of the application of bar as the basic element for deployable structures, they are further divided into scissor structures, cable-strut structures [12,13], coiled bars [4], NASA -Type Cubic [14] and structures based on Bennet mechanism [15].

Scissor structures have the greatest potential for application in architecture and civil engineering from all above mentioned. According to the application and geometry features of the bar elements, scissor structures are divided into three groups, described and presented in Table 4.:

a) classic bars connected by a scissor hinge;

b) modified bars connected by scissor hinge or hinges;

c) scissor units combined with cables.

Some authors studied the possibility of modifying the bar elements to achieve additional adaptability of scissor structures. Akgün [16] has given the most significant contribution to the development of modified scissor-like elements by suggesting a modified bar element that, apart from the classic scissor hinge, also has additional scissor hinges aimed to increase the adaptability of the system. His research served as an inspiration to scientists who studied additional adaptability of scissor structures. The change in the geometry of the traditional bar elements opens up a large number of possible variations when it comes to the formation of these structures.

The presented classification also includes other authors (Alegria Mira [17], El- Zanafy [18], Sala and Sastre [19], Rosenberg [20], Lu and others [21], Roovers and De Temmerman [22]) who have made a significant contribution to the development of modified scissor-like elements. A particular group in this category includes the structures based on the principles of "circular package" that allows the transformation of a specific geometric shape into circle systems into which scissor units are installed, thus allowing 
their assembly into compact geometrical forms. This system has been proposed by Roovers and De Temmerman (2015).

Table 4. New classification of deployable structures (part 1/2).

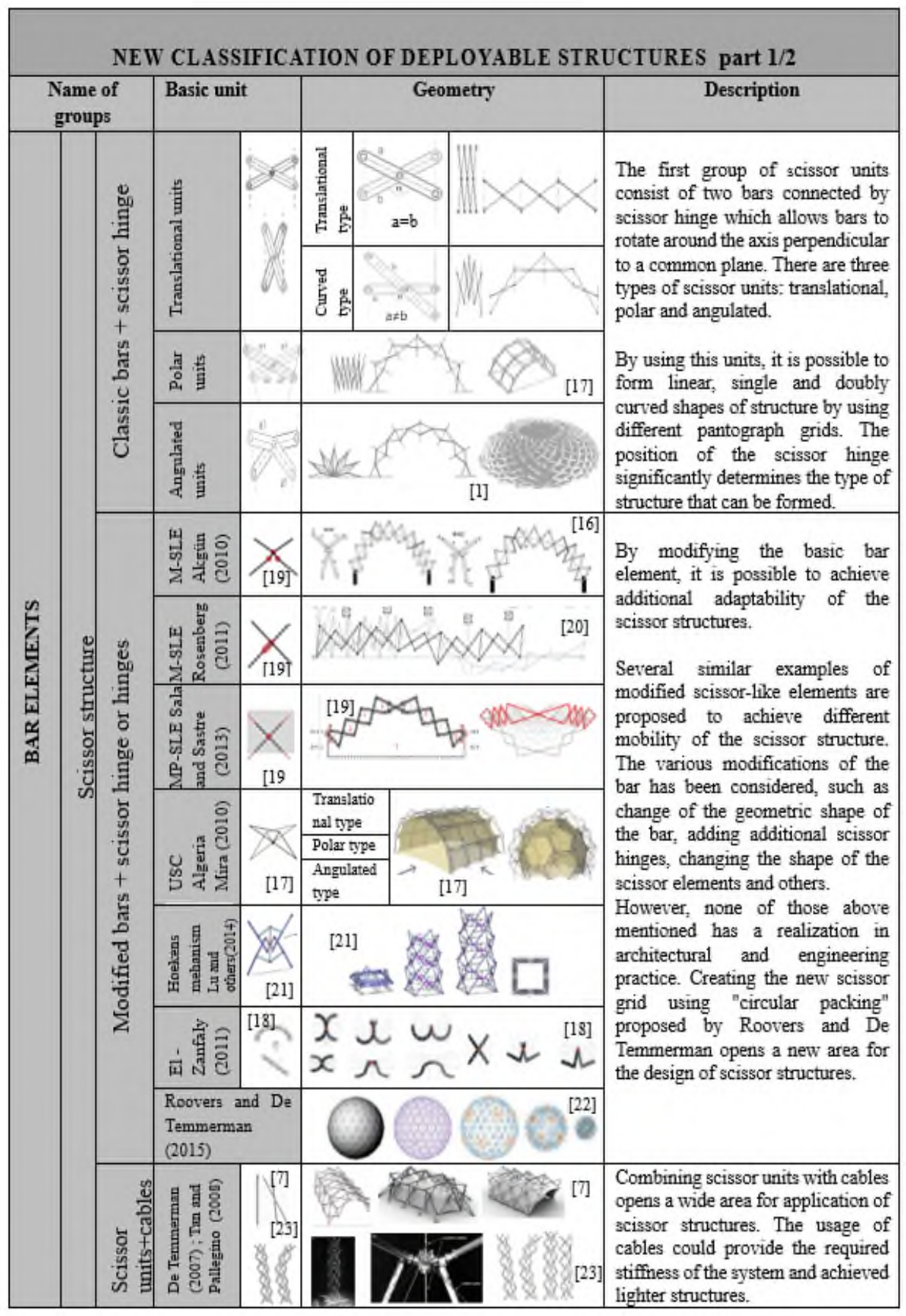

Cables in deployable scissor structures, apart from additionally increasing stiffness, make the structure significantly lighter (examples [7] and [23]). According to [7] the usage 
of the pre-stressing cable would contribute to the improvement of the structural characteristics of those systems.

Table 5. New classification of deployable structures (part 2/2).

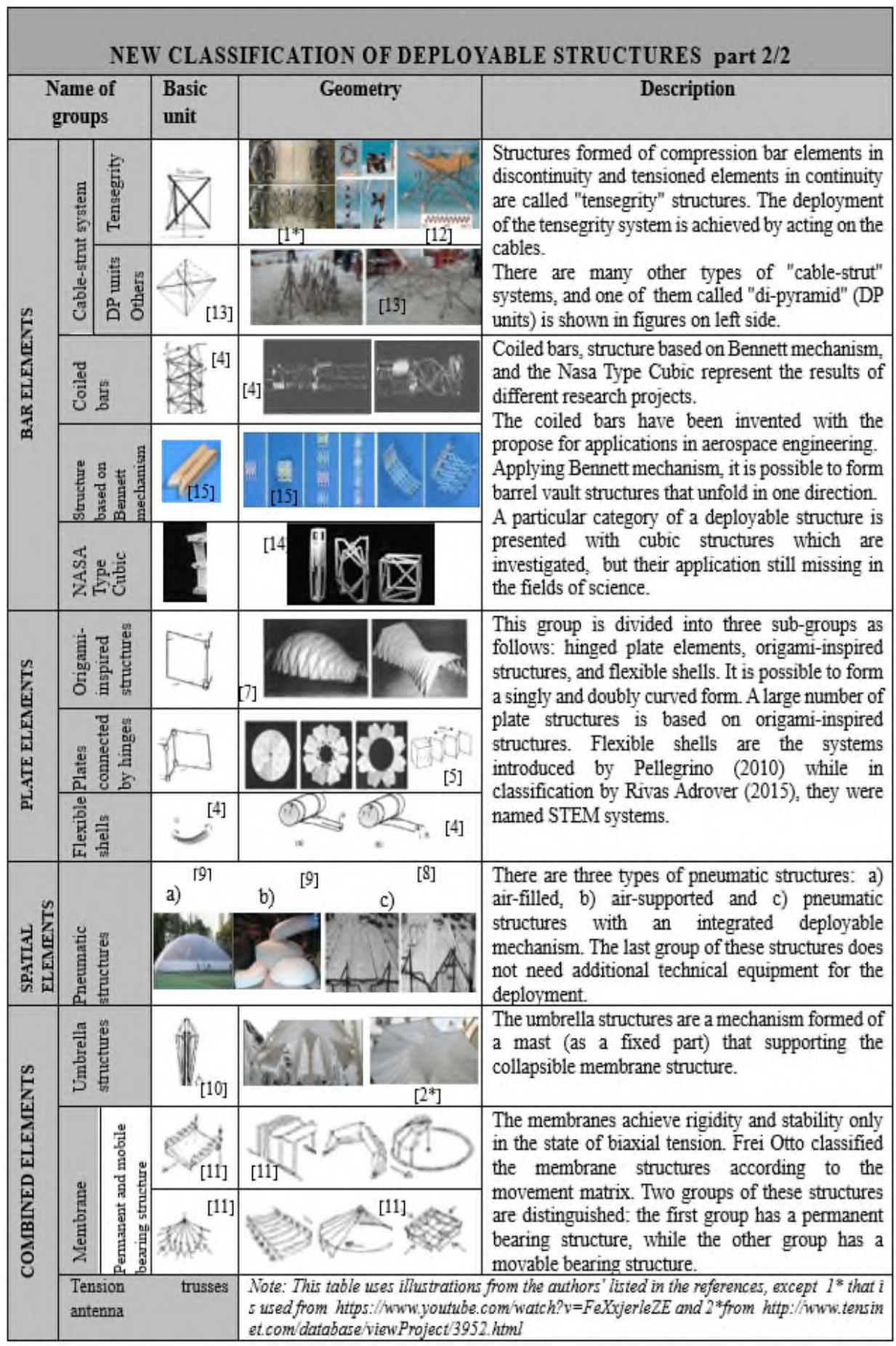


Cable-strut systems have been created by the combination of classic struts with cables. There are many cable-strut systems, but just two of them (tensegrity and "di-pyramid") are shown in Table 5. Tibert [12] proposed the possibility of applying different geometric forms of deployable tensegrity structures, such as mast and antenna. Coiled bars are the third group of deployable bar structures and are presented in details in classification by Pellegrino. Deployable single curved structures, which include structures with the application of Bennet mechanism, are the fourth group of structures with bar elements in the classification presented here.

Other groups with their characteristics are described in Table 5.

Reciprocal structures that were previously classified in the category of deployable bar structures are not grouped in this paper because they are not able to fully achieve deployable configuration.

\section{Conclusion}

The suggested classification, with the review of the results of the present research, is a significant starting point for the scientists in different disciplines and it provides a detailed insight into the studied characteristics of these structures. This classification has several advantages when compared to those presented previously as it gives the possibility to add certain structures developed over time, without changing the basic divisions and contexts. This proposal of a unified classification of deployable structures enables a multidisciplinary approach to further research, application, as well as to the development of new systems of deployable structures. A simpler approach to the basic information shall create a stronger interest in a deployable structure research that would result in a larger number of studies with specific application of these structures in various scientific fields.

\section{References}

1. A. Hanor, and R. Levy, „Evaluation of deployable structures for space enclosures”, International Journal of Space Structures 16, 4, 211-228 (2001) https://doi.org/10.1260/026635101760832172

2. A. Šljivić, Primjena lakih sklopivo-rasklopivih štapnih konstrukcija u arhitekturi, Ph.D. Dissertation, University of Sarajevo, Faculty of Architecture (2019)

3. F. Escrig, General Survey of Deployability in Architecture, Transactions on the Built Environment 21, 3-22 (1996) DOI: 10.2495/MRS960011

4. S. Pellegrino, Deployable Structure (Springer-Verlag Wien GmbH, 2001)

5. C. Gantes, A design methodology for deployable structure (Ph.D. Dissertation, Massachusetts Institute of Technology, Cambridge, 1991)

6. K. Korkmaz, An analytical study of the design potentials in kinetic architecture (Ph.D. Dissertation, İzmir Yüksek Teknoloji Enstitüsü, Izmir, 2004)

7. N. De Temmerman, Design and Analysis of Deployable Bar Structures for Mobile Architectural Applications (Ph.D. Dissertation, Vrije Universiteit Brussel, Faculty of Engineering, Department of Architectural Engineering Sciences, Brussel, 2007)

8. A.E. Del Grosso, and P. Basso, Deployable structures, Advances in Science and Technology 83, 122-131 (2015)https://doi.org/10.4028/www.scientific.net/AST.83.122

9. E. Rivas Adrover, Deployable structure (London: Laurence King Publishing Ltd., 2015) 
10. F. Escrig, New Designs and Geometries of Deployable Scissor Structures, Adaptable 2006, TU/e, International Conference On Adaptable Building Structures Eindhoven (2006)

11. N. Friedman, Investigation of highly flexible deployable structures: review, modelling, control, experiments and application (Ph.D. Dissertation, Ecole Normale Superieure de Cachan and Budapest University of Technology and Economics., Cachan and Budapest, 2011)

12. G. Tibert, Deployable tensegrity structures for space applications (Ph.D. Dissertation, Royal Institute of Technology Department of Mechanics, Stockholm, Sweden, 2002)

13. J. Cai, R. Ma, X. Deng, J. Feng, Static behavior of deployable cable-strut structures, $\begin{array}{lllll}\text { Journal of Constructional Steel Research 119, 63-75 } & \end{array}$ (2016)https://doi.org/10.1016/j.jcsr.2015.12.003

14. A.l. Britt, and H. Lalvani, Symmetry as a Basis from Morphological Analysis and Generation of Nasa-Type Cubic Deployables. IUTAM-IASS Symposium on Deployable Structures: Theory and Applications_S. Pellegrino and S. D. Guest (eds), 45-54. Kluwer Academic Publishers (2000)

15. N. O. Melin, Application of Bennett mechanisms to long-span shalters (Ph.D. Dissertation, University of Oxford, Department of Engineering Science, Oxford, 2004)

16. Y. Akgün, A novel transformation model for deployable scissor-hinge structures (Ph.D. Dissertation. Stuttgart: Universität Stuttgart, Institut für Leichtbau Entwerfen und Konstruieren, 2010)

17. L. Algeria Mira, Design and analysis of a universal scissor component for mobile architectural applications (Master Thesis, Vrije Univeriteit Brussel, Brussel, 2010)

18. D. E. El-Zanfaly, Active shapes: introducing guidelines for designing kinetic architectural structures (Master Thesis, Massachusetts Institute of Technology, Department of Architecture, 2011)

19. M.B. Sala, and R.S. Sastre, ,,Mobility and transformability in architectural structures. Proposal of a transformable system of telescopic and X-articulated bars: kinematic, geometric, and structural analysis", Proceedings of the First Conference Transformables 2013. In the Honor of Emilio Perez Piñero 18-20th September, 1-6, School of Architecture, Seville, Spain (2013)

20. D. Rosenberg, Designing for uncertainty: novel shapes and behaviors using scissorpair transformable structures (Master Thesis, Massachusetts Institute of Technology, Cambridge, 2009)

21. Sh. Lu, D. Zlatanov, X. Ding, and R. Molfino, A new family of deployable mechanisms based on the Hoekens linkage, Mechanism and Machine Theory 73, 130-153 (2014) https://doi.org/10.1016/j.mechmachtheory.2013.10.007

22. K. Roovers, and N. De Temmerman, Digital design of deployable scissor grids based on circle packing, Proceedings of the IASS 2015 Symposium "Future Visions, Amsterdam (2015)

23. G.E.B Tan, and S. Pellegrino, Nonlinear vibration of cable-stiffened pantographic deployable structures, Journal of Sound and Vibration 314, 783-802 (2008) https://doi.org/10.1016/j.jsv.2008.01.022 